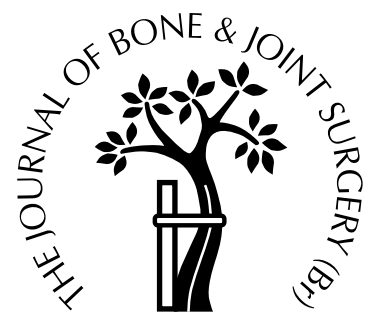

\title{
The Baumann procedure for fixed contracture of the gastrosoleus in cerebral palsy
}

\author{
EVALUATION OF FUNCTION OF THE ANKLE AFTER \\ MULTILEVEL SURGERY
}

\author{
V. Saraph, E. B. Zwick, C. Uitz, W. Linhart, G. Steinwender \\ From Karl Franzens University, Graz, Austria
}

W e treated 22 children ( 28 limbs) with diplegic cerebral palsy who were able to walk by the Baumann procedure for correction of fixed contracture of the gastrosoleus as part of multilevel single-stage surgery to improve gait. The function of the ankle was assessed by clinical examination and gait analysis before and at two years (2.1 to 4.0) after operation. At follow-up the ankle showed an increase in dorsiflexion at initial contact, in single stance and in the swing phase. There was an increase in dorsiflexion at initial push-off without a decrease in the range of movement of the ankle, and a significant improvement in the maximum flexor moment in the ankle in the second half of single stance. There was also a change from abnormal generation of energy in mid-stance to the normal pattern of energy absorption. Positive work during push-off was significantly increased. Lengthening of the gastrocnemius fascia by the Baumann procedure improved the function of the ankle significantly, and did not result in weakening of the triceps surae. We discuss the anatomical and mechanical merits of the procedure.

J Bone Joint Surg [Br] 2000;82-B:535-40.

Received 26 January 1999; Accepted after revision 16 May 1999

Equinus deformity is commonly encountered in children with cerebral palsy. Good function of the foot is essential for normal gait. The heel, ankle and forefoot rockers optimise the shock-absorbing, stabilising, and propulsive functions of the foot. Equinus causes a decrease in the stability

V. Saraph, MS, DNB, Clinical Fellow

E. B. Zwick, MD, Clinical Resident

C. Uitz, MD, Clinical Resident

W. Linhart, MD, Professor and Head of Paediatric Orthopaedics

G. Steinwender, MD, Consultant Orthopaedic Surgeon

Department of Paediatric Orthopaedics, Karl Franzens University, Auen-

bruggerplatz 34, A-8036 Graz, Austria.

Correspondence should be sent to Dr G. Steinwender.

(C)2000 British Editorial Society of Bone and Joint Surgery

0301-620X/00/49850 \$2.00

VOL. 82-B, No. 4, MAY 2000 of the stance phase, loss of smooth transition of the body over the foot, and inadequate clearance of the foot in the swing phase. ${ }^{1}$ Persistent deformity interfering with gait requires lengthening of the triceps surae. A wide variety of procedures has been described for the surgical correction of equinus (Table I).

Few studies have used gait analysis to analyse objectively the outcome of different methods of lengthening of the triceps surae. Sharrard and Bernstein ${ }^{2}$ presented an eightyear follow-up of 57 patients treated either by lengthening of the tendo Achillis or by aponeurotic lengthening of gastrocnemius. They found a recurrence of equinus of $15 \%$ in aponeurotic lengthening compared with $23 \%$ in lengthening of the tendo Achillis. Their study did not include analysis of gait. Perry et $\mathrm{al}^{3}$ reported a study of the function of triceps surae before and after surgery, using electromyography and clinical analysis of gait. They found simultaneous activity in the gastrocnemius and soleus to the quick stretch test, and suggested that the Silfverskiöld test, although unreliable in the conscious patient, can give consistent results when carried out under anaesthesia. Yngve and Chambers ${ }^{4}$ compared ankle function after Vulpius lengthening of the gastrocnemius fascia for gastrocnemius contracture with Z-lengthening of tendo Achillis for contracture of the gastrosoleus. They found an equal improvement in the ankle moments and in push-off one year after surgery in both groups. Entyre et $\mathrm{al}^{5}$ studied changes in ankle function after the Vulpius procedure and Z-lengthening using electromyography and ankle kinematics. They found no difference in the outcome between the procedures. DeLuca, Giachetto and Gage ${ }^{6}$ compared the effects of Z-lengthening with those of the Baker procedure using plots of ankle movement and found better push-off after the latter operation. Rose et $\mathrm{al}^{7}$ carried out a kinematic and kinetic evaluation of the ankle one year after Baker lengthening of the gastrocnemius fascia. Their results showed improvement in dorsiflexion in the stance and swing phases. Their kinetic results demonstrated a decrease in abnormal generation of energy in mid-stance and a significant increase in late stance for push-off. In most of these studies it was not specified whether the patient had a dynamic or a fixed contracture, and whether the contracture was isolated to the gastrocnemius or a combination of the gastrocnemius and soleus. 
Table I. Different procedures described for lengthening of the triceps surae in children with cerebral palsy

\begin{tabular}{|c|c|}
\hline Study & Procedure \\
\hline Vulpius and Strofel & Inverted "V" slide lengthening of the distal gastrocnemius/soleus aponeurosis \\
\hline Silfverskiöld $^{25}$ & Transplantation of heads of origin of the gastrocnemius \\
\hline Green and McDermott ${ }^{26}$ & Lengthening of the gastrocnemius at its origin with/without neurectomy \\
\hline White $^{27}$ & Slide lengthening of tendo Achillis \\
\hline Strayer $^{17}$ & Recession of the gastrocnemius tendon distally where it blends with tendo Achillis \\
\hline Baker $^{16}$ & "Tongue in groove" slide lengthening of distal aponeurosis of gastrocnemius \\
\hline Banks $^{28}$ & Open slide lengthening of tendo Achillis \\
\hline Silver and Simon ${ }^{29}$ & Silfverskiöld procedure with selective neurectomy of gastrocnemius \\
\hline Pierrot and Murphy ${ }^{30}$ & Transplantation of insertion of tendo Achillis \\
\hline Gaines and Ford $31^{\circ}$ & Technique for determining adequate lengthening of tendo Achillis \\
\hline Garbarino and Clancy ${ }^{32}$ & Geometrical method for calculating lengthening of tendo Achillis \\
\hline Baumann and $\mathrm{Koch}^{8}$ & Intramuscular lengthening of the gastrocnemius and/or soleus \\
\hline
\end{tabular}

Intramuscular lengthening of the gastrocnemius and soleus was described by Baumann and $\mathrm{Koch}^{8}$ in 1989. It involves multiple incisions in the anterior aponeurosis of the gastrocnemius and the adjacent fascia of soleus, over the muscle bellies. We have used this procedure during the past four years for surgical correction of equinus deformity in children with cerebral palsy and we now present our results.

\section{Patients and Methods}

We studied 22 children (28 limbs) with diplegic cerebral palsy who were able to walk and who were undergoing single-stage multilevel surgery. Only those patients who showed a fixed contracture of the gastrocnemius and the soleus by a negative Silfverskiöld test (lack of dorsiflexion of the foot to neutral with the knee in flexion and in extension) under anaesthesia and who had a subsequent lengthening of the gastrocnemius and soleus by the Baumann procedure were included. The mean age at surgery was 12.6 years ( 7.4 to 16.6 ). A mean of 8.0 procedures ( 3 to 8) was carried out in each patient. All had good vision, ability to comprehend instructions and were able to walk without the use of walking aids.

Patient assessment. Clinical examination and analysis of gait were undertaken before (mean 1.0 month) and at a mean of 2.2 years (2.1 to 4.0) after surgery. Physical examination included assessment of the active and passive range of movement, as well as of fixed deformities in the joints of the lower limb. The power of various muscle groups in the leg was investigated by manual testing, and their tone was recorded according to the Ashworth scale. ${ }^{9}$ Instrumented analysis of gait, using a six-camera video based on a movement-capturing system (Motion Analysis Corporation System, California) and a floor-mounted forceplate (Kistler Instruments Ltd, Winterthür, Switzerland), provided three-dimensional kinematics, kinetics and timedistance parameters. Kinematic and kinetic parameters in the sagittal plane and relevant findings from clinical examination were used for this study.

Operative technique. The procedure has been described by Baumann and Koch. ${ }^{8}$ A medial incision, 8 to $12 \mathrm{~cm}$ long, is made at the junction of the upper and middle thirds of the lower leg (Fig. 1). By blunt dissection, the plane

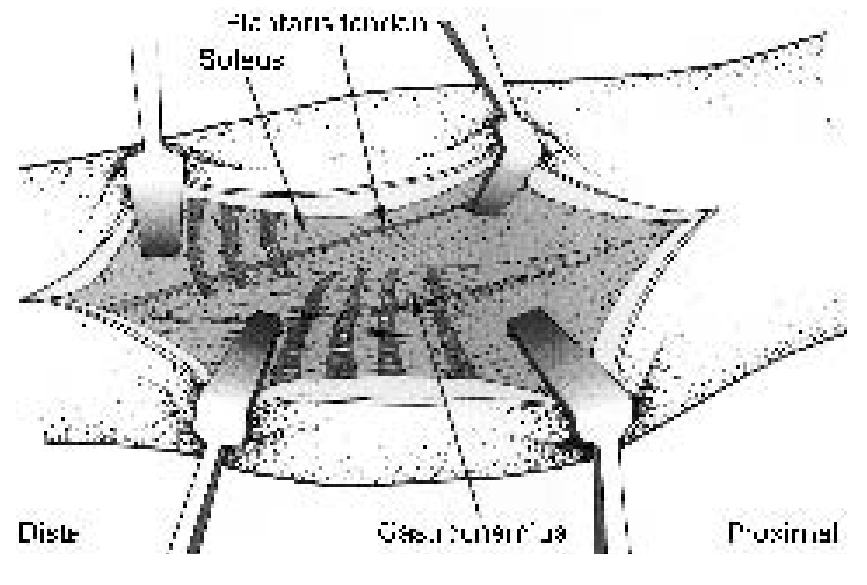

Fig. 1

Diagram to show the Baumann procedure for intramuscular lengthening of the triceps surae.

between gastrocnemius and soleus is opened. The plantaris tendon is resected. The ankle is dorsiflexed to put tension on the strong anterior aponeurosis covering the two muscle bellies of the gastrocnemius. Starting proximally the aponeurosis over the muscle bellies is divided by two or three parallel transverse incisions $1.5 \mathrm{~cm}$ apart. The septum between the medial and lateral head of the gastrocnemius is cut. The distal tendon sheet of the gastrocnemius which blends into tendo Achillis is preserved. Similar incisions for aponeurotic lengthening of the soleus are made distally to avoid overlapping with those in the gastrocnemius aponeurosis. The ankle is then gradually dorsiflexed until a neutral position is achieved with the knee in full extension, and separation of the gastrocnemius and soleus fascia can be seen. After careful haemostasis, the incision is closed in layers. Postoperatively, a short- or long-leg cast, depending on any additional procedures, is applied with the ankle in neutral.

The additional bony and/or soft-tissue procedures carried out which were specific for each patient are listed in Table II.

Postoperative management. A standard regime was used for rehabilitation after operation. Passive movement was started at four to seven days and standing in a frame and gait training by seven to ten days. Above-knee casts were applied in two patients in whom capsulotomy of the knee 
Table II. List of surgical procedures carried out on the 22 children with cerebral palsy

\begin{tabular}{lrl}
\hline Procedure & Total & Mean per patient \\
\hline Intrapelvic psoas tenotomy & 20 & 0.9 \\
Adductor lengthening & 6 & 0.3 \\
Lateral hamstring lengthening & 8 & 0.4 \\
Medial hamstring lengthening & 32 & 1.5 \\
Distal rectus transfer & 32 & 1.5 \\
Gastrosoleus lengthening & 28 & 1.3 \\
Knee capsulotomy & 2 & 0.1 \\
Foot procedures & 26 & 1.2 \\
Tibial derotation osteotomy & 8 & 0.4 \\
Femoral derotation osteotomy & 14 & 0.6 \\
Total & 176 & 8.2 \\
\hline
\end{tabular}

had been carried out. The other patients were treated by below-knee casts. These were removed at three weeks and knee-ankle-foot orthoses (KAFO) fitted to maintain knee extension during resting periods, with walking ankle-foot orthoses (AFO) to provide passive knee extension in the stance phase of gait. A KAFO was used until muscle balance at the knee was established. The AFO was discontinued when the muscle power in the calf was sufficient to stabilise the knee during stance. Stay in hospital was for four to six weeks with daily physiotherapy, and gait training. After discharge, the patients continued physiotherapy on an outpatient basis, as required, and were seen once a month in the outpatient department.
The paired Student $t$-test was used to compare the relevant kinematic, kinetic and clinical observations which were measured before operation and at follow-up. We considered $\mathrm{p}$ values of less than 0.05 to be statistically significant.

\section{Results}

At follow-up, clinical examination showed a significant improvement in active and passive dorsiflexion at the ankle, with and without knee flexion. There was no significant decrease in the power of plantar flexion of the ankle after surgery. The mean popliteal angle decreased from $55.6^{\circ}$ before to $19.5^{\circ}$ after operation.

Kinematics at the ankle showed a change in the angle at initial contact from a mean plantar flexion of $16.8^{\circ}$ to $2.2^{\circ}$. The mean angle in single stance changed from $11.8^{\circ}$ plantar flexion to $7.1^{\circ}$ dorsiflexion.

The maximum dorsiflexion of the ankle in the swing phase improved by $17.7^{\circ}(\mathrm{p}<0.0008)$. Although the ankle showed an increase in dorsiflexion of $21.9^{\circ}$ at the beginning of push-off, the total range of movement at the ankle during this phase was not affected. In the stance phase there was an increase in extension at initial contact, on singlestance and at the beginning of push-off, with maintenance of flexion during the swing (Table III).

The kinetics of the ankle in mid-stance showed a change

Table III. The mean $( \pm$ SD) kinematic and kinetic parameters evaluated

\begin{tabular}{|c|c|c|c|}
\hline Parameter & Preoperative & Postoperative & p value \\
\hline \multicolumn{4}{|l|}{ Clinical* } \\
\hline \multicolumn{4}{|l|}{ Popliteal angle in degrees } \\
\hline At knee extension (degrees) & $55.6 \pm 17.5$ & $19.5 \pm 11.3$ & 0.0013 \\
\hline Passive ankle dorsiflexion & $-16.9 \pm 9.6$ & $11.9 \pm 7.5$ & 0.0000 \\
\hline Active ankle dorsiflexion & $-21.3 \pm 7.4$ & $4.4 \pm 4.2$ & 0.0001 \\
\hline \multicolumn{4}{|l|}{ At $90^{\circ}$ knee flexion (degrees) } \\
\hline Passive ankle dorsiflexion & $-11.9 \pm 8.8$ & $16.3 \pm 7.9$ & 0.0003 \\
\hline Active ankle dorsiflexion & $-18.8 \pm 7.9$ & $9.4 \pm 4.2$ & 0.0001 \\
\hline Ankle plantar flexion power & $3.9 \pm 0.8$ & $3.5 \pm 0.5$ & 0.0796 \\
\hline \multicolumn{4}{|l|}{ Kinematics in degrees* } \\
\hline \multicolumn{4}{|l|}{ Initial contact } \\
\hline Ankle angle & $-16.8 \pm 11.7$ & $-2.2 \pm 6.0$ & 0.0017 \\
\hline Knee angle & $27.2 \pm 9.7$ & $18.9 \pm 9.6$ & 0.0424 \\
\hline \multicolumn{4}{|l|}{ Single-stance } \\
\hline Ankle angle & $-11.8 \pm 13.7$ & $7.1 \pm 5.7$ & 0.0007 \\
\hline Minimum knee angle (maximum extension) & $9.3 \pm 13.5$ & $3.5 \pm 9.5$ & 0.0553 \\
\hline \multicolumn{4}{|l|}{ Onset of push-off } \\
\hline Ankle angle & $-16.2 \pm 14.3$ & $6.9 \pm 8.7$ & 0.0006 \\
\hline Knee angle & $13.7 \pm 12.6$ & $8.9 \pm 10.4$ & 0.0329 \\
\hline \multicolumn{4}{|l|}{ Toe-off } \\
\hline Ankle angle & $-25.1 \pm 12.5$ & $-3.2 \pm 9.0$ & 0.0005 \\
\hline Push-off range of movement (ankle) & $12.9 \pm 5.0$ & $13.7 \pm 5.6$ & 0.2782 \\
\hline \multicolumn{4}{|l|}{ Maximum in swing } \\
\hline Ankle dorsiflexion & $-16.0 \pm 12.2$ & $1.7 \pm 6.2$ & 0.0008 \\
\hline Knee flexion & $59.6 \pm 11.5$ & $57.5 \pm 7.4$ & 0.7906 \\
\hline \multicolumn{4}{|l|}{ Kinetics* } \\
\hline \multicolumn{4}{|l|}{ Positive work (W/kg) } \\
\hline In single stance & $5.7 \pm 8.4$ & $-7.1 \pm 11.3$ & 0.0020 \\
\hline For push-off & $2.4 \pm 1.9$ & $5.5 \pm 2.2$ & 0.0005 \\
\hline \multicolumn{4}{|l|}{ Maximum extensor moment $(\mathrm{Nm} / \mathrm{kg})$} \\
\hline In first half of single-stance & $0.9 \pm 0.3$ & $1.0 \pm 0.3$ & 0.2511 \\
\hline In second half of single-stance & $0.7 \pm 0.3$ & $1.0 \pm 0.1$ & 0.0102 \\
\hline
\end{tabular}


Table IV. Recurrences and overcorrections from lengthening procedures described in literature

\begin{tabular}{|c|c|c|c|c|}
\hline Level & Procedure & Recurrence (\%) & Overcorrections (\%) & Reference \\
\hline Single & $\begin{array}{l}\text { Aponeurotic } \\
\text { Tendo Achillis lengthening }\end{array}$ & $\begin{array}{r}12 \text { to } 48 \\
6 \text { to } 25\end{array}$ & $\begin{array}{l}3 \\
2 \text { to } 28\end{array}$ & 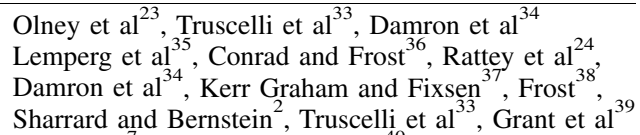 \\
\hline Multiple & $\begin{array}{l}\text { Aponeurotic } \\
\text { ATL } \\
\text { Aponeurotic or ATL } \dagger\end{array}$ & $\begin{array}{l}0 \text { to } 6 \\
5 \text { to } 22 \\
0 \text { to } 12\end{array}$ & $\begin{array}{l}0 \\
0 \text { to } 30 \\
0\end{array}$ & $\begin{array}{l}\text { Rose et } \mathrm{al}^{7} * \text {, Javors and Klaaren } \\
\text { Gaines and Ford }{ }^{31} \text {, Sala et al }{ }^{11} \text {, Segal et } \mathrm{al}^{41} * \\
\text { Yngve and Chambers }{ }^{4} \text {, Entyre et } \mathrm{al}^{5} *\end{array}$ \\
\hline
\end{tabular}

* gait analysis used for evaluation

$\dagger$ Vulpius procedure was used for gastrocnemius contracture, and tendo Achillis lengthening (ATL) for combined contractures; level indicates whether the surgical correction reported was performed as an isolated procedure or a part of multilevel surgery

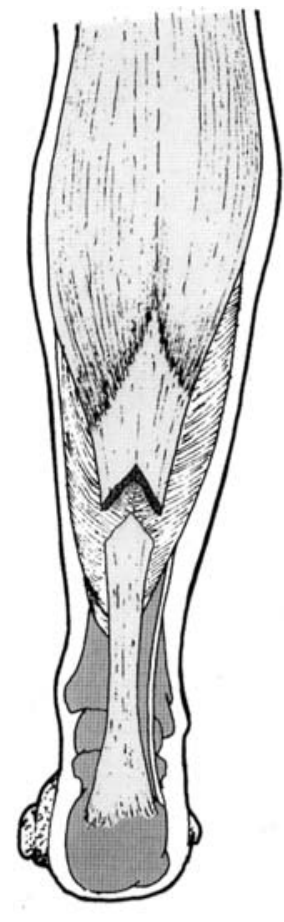

a

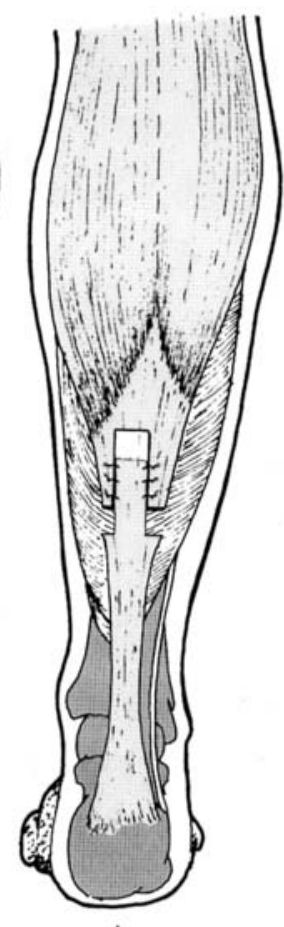

b

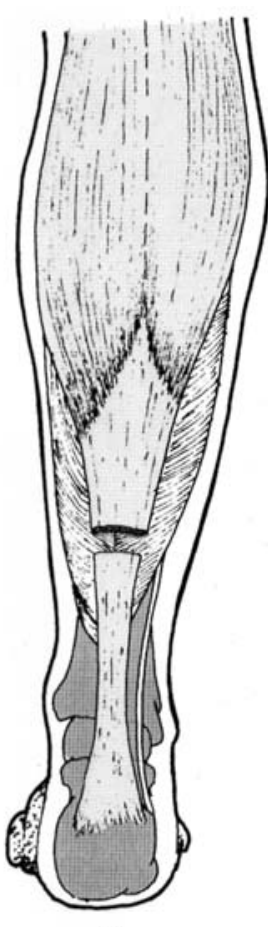

c
Fig. 3

Diagrams of other techniques of aponeurotic lengthening showing a) Vulpius b) Baker and c) Strayer. Note the proximity of surgery to the musculotendinous junction.

the normal passive range of movement, but substantially decreased the active force-generating capacity of the soleus. They suggested that independent lengthening of the contracted gastrocnemius and soleus, rather than lengthening of their common tendon, may be a more effective method of restoring range of movement and maintaining the strength of plantar flexion. Ziv et $\mathrm{al}^{14}$ showed that in the gastrocnemius muscle of normal and spastic mice, $45 \%$ of growth occurs at the musculotendinous junction. They also showed that spastic muscle grows at only $55 \%$ of the rate of bone, and this may explain the development of equinus contracture. They termed the musculotendinous junction as the 'growth plate' of the muscle. It is therefore possible that operating at this site as in the Vulpius, Baker and Strayer procedures or lengthening of tendo Achillis could further compromise the retarded growth of spastic muscle (Fig. 3). ${ }^{15-18}$ Since these procedures are not intramuscular lengthenings, they could shorten the spastic muscle and further compromise the function.

The Baumann procedure has several advantages. The Vulpius, Strayer and Baker procedures are carried out at the musculotendinous junction and lengthen the posterior gastrocnemius aponeurosis (Fig. 3). ${ }^{15-18}$ The Baumann procedure addresses the thicker and relatively inelastic anterior gastrocnemius aponeurosis (Fig. 1). If indicated, the soleus aponeurosis can also be lengthened. Multiple incisions spread the tension on the muscle fibres during subsequent stretching, and reduce the danger of stress concentration which could lead to rupture. This procedure respects the 'growth plate' of the muscle, and allows an individual correction of both muscles. The muscle power of the triceps surae after the Baumann procedure was not reduced after operation in our study. The results support the theoretical conclusions of simulation studies. ${ }^{13}$

Patients with cerebral palsy require prolonged rehabilitation and follow-up after surgery. ${ }^{19-20}$ In our study, patients required dynamic AFOs for a mean of 9.4 months and rigid KAFOs were worn at night for up to one year after surgery. The orthoses were discontinued when they were able to walk with the knee unlocked, and extension of the joint occurred in stance phase. ${ }^{21}$

A review of the literature shows that there is a higher incidence of recurrence and overlengthening after lengthening of the tendon than after aponeurotic lengthening. Sala et $\mathrm{al}^{11}$ found that increasing hamstring contracture was the major factor influencing recurrence of equinus. The age of the patient is also important, and several studies have documented a higher rate of recurrence after operation at less than six years. ${ }^{22-24}$ Awareness of the interdependancy of the deformity of joints and the concept of multilevel surgical correction have considerably improved the outcomes (Table IV). There were no recurrences or overcorrections in our study and our results compare favourably with those of Baumann and Koch. ${ }^{8}$

As a result of this study we would recommend the Baumann procedure for fixed equinus contractures in diplegic cerebral palsy. These conclusions, however, have some limitations. The effects of multilevel surgery and improvement of function at other joints undoubtedly influences the results. We rarely use other methods of lengthening of the triceps surae for equinus deformity and do not have sufficient data for a comparative study. 
This study was funded by the Gesellschaft zur Förderung der Gesundheit des Kindes, Graz, Austria.

No benefits in any form have been received or will be received from a commercial party related directly or indirectly to the subject of this article.

\section{References}

1. Perry J. Gait analysis: normal and pathological function. 1st ed. Thorofare, NJ, Slack, 1992.

2. Sharrard WJW, Bernstein S. Equinus deformity in cerebral palsy: a comparison between elongation of the tendo calcaneus and gastronemius recession. J Bone Joint Surg [Br] 1972;54-B:272-6.

3. Perry J, Hoffer MM, Giovan P, Artonelli D, Greenberg R. Gait analysis of the triceps surae in cerebral palsy: a preoperative and postoperative clinical and electromyographic study. J Bone Joint Surg [Am] 1974;56-A:511-20.

4. Yngve DA, Chambers C. Vulpius and Z-lengthening. J Pediatr Orthop 1996;16:759-64.

5. Entyre B, Chambers CS, Scarborough NH, Cain TE. Preoperative and postoperative assessment of surgical intervention for equinus gait in children with cerebral palsy. J Pediatr Orthop 1993;1:24-31.

6. DeLuca PA, Giachetto J, Gage JR. Gait lab analysis of spastic equinus deformities: a new system of standardized assessment. Dev Med Child Neurol 1988;30:16-7.

7. Rose SA, DeLuca PA, Davis RB III, Ounpuu S, Gage JR. Kinematic and kinetic evaluation of the ankle after lengthening of the gastrocnemius fascia in children with cerebral palsy. J Pediatr Orthop 1993;13:727-32.

8. Baumann JU, Koch HG. Ventrale aponeurotische Verlängerung des Musculus gastrocnemius. Operat Orthop Traumatol 1989;1:254-8.

9. Ashworth B. Preliminary trial of carisoprodol in multiple sclerosis. Practitioner 1964;192:540-2

10. Sutherland DH, Cooper L. The pathomechanics of progressive crouch gait in spastic diplegia. Orthop Clin North Am 1978;9:143-54.

11. Sala DA, Grant AD, Kummer FJ. Equinus deformity in cerebral palsy: recurrence after tendo Achilles lengthening. Dev Med Child Neurol 1997;39:45-8.

12. Kawakami Y, Ichinose Y, Fukunaga T. Architectural and functional features of human triceps surae muscles during contraction. J Appl Physiol 1998;85:398-404.

13. Delp SL, Statler K, Carroll NC. Preserving plantar flexion strength after surgical treatment for contracture of the triceps surae: a computer simulation study. J Orthop Res 1995;13:96-104.

14. Ziv I, Blackburn N, Rang M, Koreska J. Muscle growth in normal and spastic mice. Dev Med Child Neurol 1984;26:94-9.

15. Vulpius O, Strofel A. Orthopädische Operationslehre. In: Enke Ferdinand, First edition. Stuttgart, 1911;29-30.

16. Baker LD. Triceps surae syndrome in cerebral palsy: an operation to aid in its relief. Arch Surg 1954;68:216-21.

17. Strayer LM. Recession of the gastrocnemius: an operation to relieve spastic contracture of the calf muscles. J Bone Joint Surg [Am] 1950;32-A:671-6.

18. Strayer LM. Gastrocnemius recession: five-year report of cases. $J$ Bone Joint Surg [Am] 1958;40-A:1019-30.

19. Reimers J. Functional changes in the antagonists after lengthening the agonists in cerebral palsy: II. quadriceps strength before and after distal hamstring lengthening. Clin Orthop 1990;253:35-7.
20. Nene AV, Evans GA, Patrick JH. Simultaneous multiple operations for spastic diplegia: outcome and functional assessment of walking in 18 patients. J Bone Joint Surg [Br] 1993;75-B:488-94.

21. Bleck EE. Goals, treatment and management. In: Orthopaedic management in cerebral palsy Mac Keith Press, London, 1987:175-83.

22. Craig JJ, Van Huren J. The importance of gastrocnemius recession in the correction of equinus deformity in cerebral palsy. $J$ Bone Joint Surg [Br] 1976;58-B:84-7.

23. Olney BW, Williams PF, Menelaus MB. Treatment of spastic equinus by aponeurosis lengthening. J Pediatr Orthop 1988;8:422-5.

24. Rattey TE, Leahey L, Hyndman J, Brown DC, Gross M. Recurrence after Achilles tendon lengthening in cerebral palsy. $J$ Paediatr Orthop 1993;13:184-7.

25. Silfverskiöld N. Reduction of the uncrossed two-joints muscles of the leg to one-joint muscles in spastic conditions. Acta Chir Scand 1923-24;56:315-30

26. Green WT, McDermott LF. Operative treatment of cerebral palsy of spastic type. JAMA 1942;118:434-40.

27. White JW. Torsion of the Achilles tendon: its surgical significance Arch Surg 1943;46:784-7.

28. Banks HH. The management of spastic deformities of the foot and ankle. Clin Orthop 1977;122:70-6.

29. Silver CM, Simon SD. Gastrocnemius-muscle recession (Silfverskiold operation) for spastic equinus deformity in cerebral palsy. $J$ Bone Joint Surg [Am] 1959;41-A:1021-8.

30. Pierrot AH, Murphy OB. Heel chord advancement: a new approach to the spastic equinus deformity. Orthop Clin North Am 1974;5:117-26.

31. Gaines RW, Ford TB. A systemic approach to the amount of Achilles tendon lengthening in cerebral palsy. $J$ Pediatr Orthop 1984;4:448-51.

32. Garbarino JL, Clancy M. A geometric method of calculating tendo Achilles lengthening. J Pediatr Orthop 1985;5:573-8.

33. Truscelli D, Lespargot A, Tardieu G. Variations in the long-term results of elongation of the tendo Achillis in children with cerebral palsy. J Bone Joint Surg [Br] 1979;61-B:466-9.

34. Damron TA, Greenwald TA, Breed AL. Chronologic outcome of surgical tendo Achilles lengthening and natural history of gastrocsoleus contracture in cerebral palsy: a two part study. Clin Orthop 1994;301:249-55

35. Lemperg R, Hagberg B, Lundberg A. Achilles tenoplasty for correction of equinus deformity in cerebral palsy of spastic type. Actc Orthop Scand 1969;40:507-19.

36. Conrad JA, Frost HM. Evaluation of subcutaneous heel-cord lengthening. Clin Orthop 1969;64:121-7.

37. Kerr Graham H, Fixsen JH. Lengthening of the calcaneal tendon in spastic hemiplegia by the white slide technique. J Bone Joint Surg [Br] 1988;70-B:472-5.

38. Frost HM. Surgical treatment of spastic equinus in cerebral palsy. Arch Phy Med Rehabil 1971;52:270-5.

39. Grant AD, Feldman R, Lehman WB. Equinus deformity in cerebral palsy: a retrospective analysis of treatment and function in 39 cases. $J$ Pediatr Orthop 1985;5:678-81.

40. Javors JR, Klaaren HE. The Vulpius procedure for correction of equinus deformity in cerebral palsy. J Pediatr Orthop 1987;7:191-3.

41. Segal LS, Thomas SE, Mazur JM, Mauterer M. Calcaneal gait in spastic diplegia after heel cord lengthening: a study with gait analysis. J Pediatr Orthop 1989;9:697-701. 